Article

\title{
Phubber's Emotional Activations: The Association between PANAS and Phubbing Behavior
}

\author{
Andrea Guazzini ${ }^{1,2}{ }^{(}$, Tommaso Raimondi $^{1}\left(\mathbb{D}\right.$, Benedetta Biagini ${ }^{1}$, Franco Bagnoli ${ }^{2,3}$ and Mirko Duradoni ${ }^{1, *}$ \\ 1 Department of Education, Literatures, Intercultural Studies, Languages and Psychology, University of \\ Florence, 50135 Florence, Italy; andrea.guazzini@unifi.it (A.G.); tommaso.raimondi@stud.unifi.it (T.R.); \\ benedetta.biagini1@stud.unifi.it (B.B.) \\ 2 Centre for the Study of Complex Dynamics, University of Florence, 50019 Sesto Fiorentino, Italy; \\ franco.bagnoli@unifi.it \\ 3 Department of Physics and Astronomy, University of Florence, 50019 Sesto Fiorentino, Italy \\ * Correspondence: mirko.duradoni@unifi.it
}

Citation: Guazzini, A.; Raimondi, T.; Biagini, B.; Bagnoli, F.; Duradoni, M. Phubber's Emotional Activations: The Association between PANAS and Phubbing Behavior. Future Internet 2021, 13, 311. https://doi.org/ 10.3390/fi13120311

Academic Editor: Svetlana S. Bodrunova

Received: 15 November 2021 Accepted: 2 December 2021 Published: 4 December 2021

Publisher's Note: MDPI stays neutral with regard to jurisdictional claims in published maps and institutional affiliations.

Copyright: (c) 2021 by the authors. Licensee MDPI, Basel, Switzerland. This article is an open access article distributed under the terms and conditions of the Creative Commons Attribution (CC BY) license (https:// creativecommons.org/licenses/by/ $4.0 /)$.

\begin{abstract}
Currently, mobile phones are widely used worldwide. Thus, phubbing rapidly became a common phenomenon in our social life. Phubbing is considered by the literature as a new form of technology-related addiction that may undermine interpersonal relationships and mental health. Our study contributed to exploring phubbers' emotional activation as no other work has investigated it so far. Indeed, researchers have only explored phubbees' but not phubbers' emotional correlates. A sample of 419 Italian individuals (143 males) participated in our data collection on a voluntary basis. The results showed that phubbing is related to negative affects, but not to positive affects. Moreover, phubbing in both its components (i.e., communication disturbance, phone obsession) appeared to elicit an emotional activation similar to that of social media addiction. These findings may help in strengthening the discussion around the emotional consequences of virtual environment design, as well as the awareness about what happens at a relational level during phubbing.
\end{abstract}

Keywords: phubbing; social media addiction; emotional activation; PANAS

\section{Introduction}

The disruptive impact of web-based communication drastically changed people's way of socializing [1]. Nowadays, people can interact with many others at the same time regardless of the physical presence of the interactor, both in a synchronous or an asynchronous way [2]. In this sense, the "social situation" transcends physical space and can embrace both real and virtual environments [3,4]. A recent study from Simon Kemp and Datareportal [5] revealed that the number of global social media users grew rapidly in the latest years, reaching nearly 4 billion users at the beginning of July 2020. In other words, more than half of the world's population is now using social media regularly [6]. Especially adolescents are particularly keen to use their smartphones, with 95\% of teens reported having a smartphone and $45 \%$ of them said to be online 'almost constantly' [7].

The growth already underway in the use of new technologies has been accentuated even more by the pandemic. Indeed, in the current Covid-19 pandemic period, information and communication technologies (ITC) allowed people to partially compensate for the reduced social physical connectedness, offering the possibility to communicate with others, as well as to maintain their social relationships and networks [8]. However, despite their obvious advantages in bringing people together, smartphones and ICT, in general, may sometimes pull people apart and promote social "dysfunctional" behaviors [9-11].

Among these, phubbing has recently received increasing attention from scientists [1,12-14]. Phubbing describes smartphone usage that socially interferes in face-to-face interactions and refers to the act of "snubbing" or ignoring someone in a social context, preferring the use of the smartphone [12]. 
In our societies, phubbing is very diffuse, reciprocally reinforced, and socially accepted, such that we can observe it in a plethora of social situations (e.g., while eating with someone, during a drink or coffee break with colleagues, in family interactions) $[1,15,16]$. Indeed, the prevalence of phubbing in social interaction is estimated to range from $44 \%$ to $90 \%[1,17,18]$.

Phubbers (i.e., those who ignore their face-to-face interactor) appeared to be characterized by higher levels of technology-related addiction (e.g., mobile phone addiction, social media addiction, Internet addiction, mobile game addiction), psychological disorders (i.e., depression, social interaction anxiety, social withdrawal, nomophobia) [13,19-24], and trait boredom [25].

Despite that phubbing and social media addiction dynamics showed a positive correlation, they should be studied as two different phenomena. In the work of Guazzini and colleagues [13], the results highlighted a strong connection between phubbing and online addiction behaviors (e.g., social media addiction, Internet addiction), as well as with psychological and psychosocial determinants of online compulsive behaviors (i.e., trait and social anxiety). Their model was able to explain approximately $36 \%$ of the phubbing variance and, in particular, social media addiction accounted only for $7.2 \%$ of it.

Phubbing and social media appeared closely related, as one of the motivations for phubbing is to check the mobile social media apps that are increasingly pervasive and accessible in our society $[5,6,13]$. However, as addiction variables related to information and communication technologies were unable to fully explain phubbing, phubbing and social media addiction-related factors may be different. Despite this evidence, individual differences research pointed out some important relations between phubbing and social media addiction. For example, both sex $[1,12,26,27]$ and age $[13,28]$ appeared to be associated with social media addiction and phubbing with a similar magnitude, with women and young people appearing to be more exposed to phubbing and social media addiction. Furthermore, research widely assessed that being addicted to smartphone, social media, or the Internet has negative repercussions on the well-being of the person [29-34] as well as being a phubber $[1,17,26]$ or a phubbed $[35,36]$.

The current literature, despite having extensively analyzed the effect that social media addiction has in terms of affective hedonic well-being [37-39], did not explore the relationship between phubbing and emotional activation with the same depth. Indeed, at the moment, only a few works studied the emotional impact of being phubbed [35,40,41], while no work has studied phubbers' emotional correlates. Knowing phubber emotional activation is crucial to gain the full picture of what is really going on in the phubbing situation, as emotions are very important in shaping human relationality [42].

\section{Aim of the Study and Development of Hypotheses}

Our study aims to fill the gap currently present in the literature regarding the emotional activation of phubber and compare it with that of social media addiction (SMA). Indeed, some works have already studied the emotional correlates of being exposed to phubbing both as a phubbing target (phubbee, [41]) and as a third-party observer of the phubbing dynamics [43]. However, no study so far investigated the emotional activation of the individual that engages in phubbing in terms of well-being. Only the work of Bitar and colleagues [44] has explored in a pioneering way the relationship between phubbing and temperament, which, however, was intended by the authors as a biological core of personality and not a component of hedonic well-being. To achieve our aim, it was necessary to take into account previous research that identified two potentially impacting characteristics for phubbing and SMA: sex and age.

The literature reported how females seem to have higher phubbing scores than males $[1,12,27,45]$. The same type of relationship was identified in the literature for social media addiction $[26,28,30,46]$. Regarding the relationship between sex and emotional activation, the results do not appear to be definitive. Indeed, sex differences were not found in the U.S. normative sample [47], while sex-related differences in emotional activation scores were observed in other works [47-49]. Specifically, where sex differences were detected, 
females tended to have higher scores than men in terms of the negative affect, but not in terms of the positive affect. Nonetheless, given the contradictory results in the literature findings, the relationship between sex and emotional activation will be explored without producing hypotheses. Regarding age, the research has essentially identified that younger people appeared to be more disposed to phubbing $[13,25,50]$. A lower age seems to also be a significant predictor for SMA [28,30,51].

Although both SMA and phubbing are considered two different constructs, the scientific literature points out that they are strongly correlated with each other $[12,13,26,52]$. In our study, we expect that this relationship would remain the same and with a similar effect size (i.e., ranging between 0.46 and 0.65 Pearson's $r$ values).

In line with the scientific literature, we also expect that SMA is associated with lower levels of hedonic affective well-being. In particular, research reported how people with SMA experienced lower levels of positive affect and higher levels of negative affect [30-33].

Because of the close relationship between phubbing and social media addiction [12,13,26,52], we expect to find an emotional activation in phubbing in line with the one revealed for social media addiction. As the data on the emotional activation of phubbing are completely absent in the literature, the hypotheses on this aspect are to be considered exploratory.

Based on the literature evidence, the following hypotheses were formulated for this study:

Hypothesis 1 (H1). Females will have higher scores on the phubbing scale.

Hypothesis 2 (H2). Females will report higher scores on the social media addiction scale.

Hypothesis 3 (H3). Phubbing is negatively correlated with age.

Hypothesis 4 (H4). Social media addiction is negatively correlated with age.

Hypothesis 5 (H5). Social media addiction positively correlates with phubbing, after controlling for age and sex.

Hypothesis 6 (H6a). Social media addiction positively correlates with negative affect (NA) after controlling for age and sex.

Hypothesis $6 \mathbf{( H 6 b ) . ~ S o c i a l ~ m e d i a ~ a d d i c t i o n ~ n e g a t i v e l y ~ c o r r e l a t e s ~ w i t h ~ p o s i t i v e ~ a f f e c t ~ ( P A ) ~ a f t e r ~}$ controlling for age and sex.

Hypothesis 7 (H7a). Phubbing positively correlates with NA after controlling for age and sex.

Hypothesis 7 (H7b). Phubbing negatively correlates with PA after controlling for age and sex.

\section{Material and Methods}

\subsection{Materials}

The phubbing scale [12] was used to determine phubbing behaviors. It consists of 10 items graded from 1 (never) to 5 (always) on a five-point Likert scale. This instrument assesses phubbing as a combination of two main components. The first is phone obsession (PO; 5 items; $\alpha=0.85$ ): high scores indicate that the person feels the constant need for his/her smartphone in an environment where there's a lack of face-to-face communications. An example of this factor's items is "When I wake up in the morning, I first check my messages on my phone". The second is communication disturbances (CD; 5 items; $\alpha=0.87$ ): high scores indicate that the person often disturbs the communication using the smartphone in a face-to-face environment. An example of this factor's items is "I'm dealing with my mobile phone when I'm with my friends". In our study, we relied on the same Italian adapted items used by Guazzini and colleagues [13] that provided a preliminary validation of the scale in the Italian context. 
The social media addiction scale [12] was used to determine social media addiction. This scale consisted of ten items ranging from 1 (never) to 5 (always) on a five-point Likert scale. It consists of only one factor and the Cronbach's alpha coefficient for the scale was 0.80. Some examples of items were "I keep online the messaging applications all the time" and "I feel a need to reply the messages instantly". Moreover, in this case, the items were those preliminary validated in the Italian context by Guazzini and colleagues [13].

The positive and negative affect schedule [47] was used to determine affective components defined as stable traits of hedonic well-being. This scale is the Italian version of the PANAS [53] and the measure consists of 20 adjectives graded from 1 (very slightly or not at all) to 5 (extremely) on a five-point Likert scale and asks to indicate how the participant generally felt. PA (10 items; $\alpha=0.72)$ : the positive affect scale reflects the level of pleasant engagement, that is, the extent to which a person feels enthusiastic, excited, or active; NA (10 items; $\alpha=0.83$ ): the negative affect scale reflects a general dimension of unpleasant engagement and subjective distress that subsumes a broad range of aversive affects including fear, nervousness, guilt, and shame.

\subsection{Sample and Procedure}

Before proceeding with the recruitment phase, we performed the power analysis to establish an adequate sample size for our research purposes. We relied on G*Power software to accomplish this procedure [54,55]. Power analysis allows researchers to determine the sample size required to detect an effect of a given size with a given degree of confidence. For each type of statistical analysis, a power analysis should be performed, and the final sample size should be evaluated based on the power analysis that requires the largest sample size. The power analysis showed that a sample size of 139 individuals for each level of the variable "sex" would be enough to ensure a statistical power of 0.80 , assuming a medium effect size $(d=0.30)$ and a significance level of 0.05 , to assess sex-related differences. For Pearson correlation, a sample of 364 would be required to achieve the same statistical power (i.e., 0.80), while assuming a smaller effect size $(\mathrm{r}=0.13)$. Moreover, as our study is mainly based on correlation, we considered the sample size for achieving a stable measurement-error-free correlation. In our case (i.e., population correlation $q=0.10$; composite score reliability derived from other works $\omega=0.80$ ), a stable measurement-error-free correlation would be achieved at 380 [56].

Given the exploratory nature of the present work, the authors chose a nonprobability method based on the voluntary census to test their hypotheses. In these circumstances, studies based on voluntary participation can be considered satisfying [57]. A total of 419 participants (143 males) with an average age of 30.80 (standard deviation $=12.68$ ) were recruited on the web and provided their informed consent. More details about the sample composition are reported in the Appendix A (Table A1).

The study involved an anonymous online survey on the Google Forms platform. The Google form was set to allow only one response per user and included two attention checks to identify faulty answers. Inclusion criteria were age 18 years or older and being an Italian citizen. The meeting of inclusion criteria was self-certified.

The questionnaires were administered to the participants according to the Italian law's requirements of privacy and informed consent (Law Decree DL-101/2018), EU regulation (2016/699), and APA guidelines. The participants were allowed to leave the session at any moment, as clearly stated in the preliminary instructions. Seven participants did not provide their informed consent, and thus ended the session without answering the survey.

\subsection{Data Analysis}

The preconditions necessary for inferential analyses were verified on the data collected. For all the continuous variables under investigation, the normality of the distribution was assessed through the analysis of asymmetry and kurtosis values. Common-method bias was also assessed with Harman's single-factor test [58]. To test sex-related differences, we relied on Welch's $t$-test, as it performs better than Student's $t$-test whenever sample 
sizes and variances are unequal between groups, and gives the same result when sample sizes and variances are equal [59]. Age-related differences in phubbing, social media addiction, and affective activations were assessed by Pearson correlation. Finally, the partial correlation was employed to estimate phubbing and social media relationships with positive and negative affects after controlling for both age and sex.

\section{Results}

\subsection{Descriptive Statistics}

Table 1 reports the descriptive statistics for all the continuous observables involved in our data collection. All variables appeared normally distributed except for guilty and ashamed activations, which exceeded the threshold of +1 and -1 .

Table 1. Descriptive statistics.

\begin{tabular}{ccccccc}
\hline Variables & Min & Max & M & SD & Asym. & Kurt. \\
\hline Communication Disturbance & 5 & 22 & 9.76 & 3.08 & 0.71 & 0.72 \\
Phone Obsession & 6 & 22 & 15.07 & 3.04 & -0.23 & -0.30 \\
Social Media Addiction & 10 & 47 & 27.91 & 5.90 & -0.26 & 0.18 \\
Determined & 1 & 5 & 3.28 & 0.89 & 0.11 & 0.34 \\
Active & 1 & 5 & 3.17 & 0.80 & 0.24 & 0.01 \\
Interested & 1 & 5 & 3.53 & 0.85 & -0.01 & -0.26 \\
Attentive & 1 & 5 & 3.30 & 0.94 & -0.04 & -0.34 \\
Enthusiastic & 1 & 5 & 3.12 & 0.93 & 0.08 & 0.02 \\
Concentrating & 1 & 5 & 2.96 & 0.91 & 0.28 & -0.21 \\
Strong & 1 & 5 & 2.85 & 0.95 & 0.21 & -0.13 \\
Inspired & 1 & 5 & 2.97 & 0.95 & 0.27 & -0.30 \\
Excited & 1 & 5 & 2.65 & 0.88 & 0.23 & -0.17 \\
Proud & 1 & 5 & 3.00 & 1.03 & 0.15 & -0.45 \\
Afraid & 1 & 5 & 2.35 & 1.10 & 0.56 & -0.38 \\
Upset & 1 & 5 & 2.31 & 1.05 & 0.59 & -0.19 \\
Nervous & 1 & 5 & 2.53 & 1.05 & 0.51 & -0.23 \\
Jittery & 1 & 5 & 2.40 & 1.05 & 0.53 & -0.27 \\
Scared & 1 & 5 & 2.05 & 1.04 & 0.98 & 0.54 \\
Distressed & 1 & 5 & 2.12 & 1.05 & 0.75 & -0.01 \\
Guilty & 1 & 5 & 1.57 & 0.87 & 1.56 & 1.93 \\
Ashamed & 1 & 5 & 1.62 & 0.87 & 1.53 & 2.14 \\
Irritable & 1 & 5 & 2.35 & 1.06 & 0.60 & -0.15 \\
Hostile & 1 & 5 & 1.59 & 0.78 & 0.98 & 0.99 \\
PANAS_PA & 12 & 49 & 30.84 & 6.35 & 0.11 & 0.06 \\
PANAS_NA & 11 & 44 & 23.89 & 7.42 & 0.57 & -0.10 \\
\hline SDAs & 5 & 59 &
\end{tabular}

Note: $\mathrm{N}=419$; $\mathrm{SD}$ = standard deviation; Asym. = asymmetry; Kurt. = kurtosis.

As a first step, we proceeded by quantitatively comparing our descriptive statistics with the information provided in other studies that relied on the same measures through Student $t$-test. As for phubbing, we did not obserive a big difference in the values present in the literature [27]. By dividing our communication disturbance and phone obsession scores by the total number of the items, we obtained 1.95 (literature value $=1.99$; $\mathrm{t}_{(1014)}=-0.92 ; p=0.36$ ) and 3.01 (literature value $=2.96 ; \mathrm{t}_{(1014)}=1.04 ; p=0.30$ ), respectively. For what concerns social media addiction values, our scores and those presented in Karadag and colleagues' work [12] are just slightly different $\left(\mathrm{t}_{(826)}=4.05 ; p<0.001\right.$; Cohens' $\mathrm{d}=0.28$ ). In our case, the SMA average divided by the total number of items was 2.79 (literature value $=2.60$ ). Finally, we compared our PANAS score with those of the Italian normative sample [53]. Positive affect-related (30.84 vs. $27.6 ; \mathrm{t}_{(1017)}=7.55 ; p<0.001$; Cohens' $\mathrm{d}=0.48)$ and negative affect-related discrepancy seemed more pronounced (23.89 vs. $16.0 ; \mathrm{t}_{(1017)}=18.41 ; p<0.001$; Cohens' $\left.\mathrm{d}=1.17\right)$, probably because of the fact that our data were collected during the Covid-19 pandemic. Indeed, in a recent study conducted on the Italian population [8], both of the dimensions of PANAS seemed to have increased compared with pre-pandemic values. Overall, as the observed discrepancies were not so 
large, apart from the PANAS score, in order to fully hinder generalizability, we considered our sample suitable to proceed with inferential analyses.

\subsection{Inferential Analysis}

\subsubsection{Sex-Related Differences in Social Media Addiction and Phubbing}

To test our H1 and H2, we compared males' and females' scores on phubbing and SMA through Welch's $t$-tests, as sample sizes were unequal between groups (Table 2). The analysis showed that males and females did not have different scores in the communication disturbance dimension $\left(\mathrm{t}_{(417)}=-0.47 ; p=0.64\right)$, while a difference between males and females was captured for both phone obsession $\left(\mathrm{t}_{(417)}=-3.67 ; p=0.001\right.$; Cohen's $\mathrm{d}=-0.38$ ) and SMA $\left(\mathrm{t}_{(417)}=-5.85 ; p=0.001\right.$; Cohen's $\left.\mathrm{d}=-0.61\right)$. In general, females obtained higher scores on these dimensions, although with different magnitudes. A commonly used rule for Cohen's d interpretation distinguishes small, medium, and large effect sizes for d values of $0.2,0.5$, and 0.8 , respectively, based on benchmarks suggested by Cohen [60]. Nonetheless, this rule should not be interpreted rigidly [61]. In our study, sex differences appeared larger in size for SMA compared with those related to communication disturbance.

Table 2. Welch's t-test for assessing sex-related differences in phubbing and social media addiction.

\begin{tabular}{|c|c|c|c|c|c|c|c|}
\hline Variable & Sex & $\mathbf{M}$ & SD & $t$ & df & $p$ & Cohen's d \\
\hline $\begin{array}{c}\text { Phubbing } \\
\text { Communication Disturbance }\end{array}$ & $\begin{array}{c}\text { Males } \\
\text { Females }\end{array}$ & $\begin{array}{l}9.66 \\
9.82\end{array}$ & $\begin{array}{l}3.14 \\
3.06\end{array}$ & -0.47 & 280.40 & 0.64 & n.c. \\
\hline $\begin{array}{c}\text { Phubbing } \\
\text { Phone Obsession }\end{array}$ & $\begin{array}{l}\text { Males } \\
\text { Females }\end{array}$ & $\begin{array}{l}14.32 \\
15.46 \\
\end{array}$ & $\begin{array}{l}3.03 \\
2.97\end{array}$ & -3.67 & 282.99 & 0.001 & -0.38 \\
\hline Social Media Addiction & $\begin{array}{c}\text { Males } \\
\text { Females }\end{array}$ & $\begin{array}{l}25.62 \\
29.10\end{array}$ & $\begin{array}{l}5.90 \\
5.55\end{array}$ & -5.85 & 272.77 & 0.001 & -0.61 \\
\hline
\end{tabular}

Note: $\mathrm{N}=419 ; \mathrm{SD}=$ standard deviation; $\mathrm{df}=$ degrees of freedom; n.c. = not computed owing to a non statistically significant result.

\subsubsection{Sex-Related Differences in Positive and Negative Affects}

The same type of analysis was used to explore the sex-related differences in PANAS scores. In our sample, we were not able to capture differences between males and females concerning both positive affect $\left(\mathrm{t}_{(417)}=0.64 ; p=0.52\right)$ and negative affect $\left(\mathrm{t}_{(417)}=0.55\right.$; $p=0.58)$.

\subsubsection{Phubbing, SMA, and PANAS Correlations with Age}

The relationship between participants' age and both SMA and phubbing was assessed through Pearson's correlation. The Pearson $\mathrm{r}$ coefficient can be interpreted considering values of $0.10,0.20$, and 0.30 as relatively small, typical, and relatively large, respectively [62]. The analysis showed that age has a relatively small relationship with $C D$ $(\mathrm{r}=-0.12 ; p=0.017)$, a typical one with $\mathrm{PO}(\mathrm{r}=-0.19 ; p<0.001)$, and a relatively large one with SMA $(\mathrm{r}=-0.35 ; p<0.001)$. Overall, phubbing and SMA seemed to be associated with younger age. Subsequently, age relationships with PANAS were tested. In this case, age entertained a statistically significant and almost typical relationship in size with PA $(\mathrm{r}=-0.17 ; p<0.001)$ and a relatively large relationship with NA $(\mathrm{r}=-0.32 ; p<0.001)$. As age increases, we observed a decrease in both positive and negative affective activation, albeit with different magnitudes.

\subsubsection{Relationship between Phubbing and SMA and Phubbing Intercorrelation}

Given that both sex and age appeared to be able to influence social media addiction and phubbing levels, we relied on a partial correlation technique controlling for both participants' age and sex to investigate how phubbing and SMA relate to one another. Both $\mathrm{PO}(\mathrm{r}=0.51 ; p<0.001)$ and $\mathrm{CD}(\mathrm{r}=0.45 ; p<0.001)$ components were observed to largely correlate with SMA. Finally, both phubbing components (i.e., PO and CD) appeared largely associated with one another $(\mathrm{r}=0.51 ; p<0.001)$. 


\subsubsection{Phubbing and SMA Emotional Activations}

We relied on partial correlations once again in order to produce modeling about emotional activation related to both phubbing and SMA that could be free from the previously identified relationships regarding sex and age. For guilty and ashamed variables, a non-parametric partial correlation was performed.

In Table 3, phubbing and SMA did not seem to be related to positive affects, with a few exceptions (i.e., $\mathrm{CD}$ correlations with determined, attentive, and concentrating adjectives and the correlation between PO and concentrating). Active, interested, enthusiastic, strong, inspired, excited, and proud adjectives appeared unrelated to both phubbing scores and social media addiction.

Table 3. Partial correlation of PANAS with both phubbing (CD and PO) and SMA (controlled for age and sex). Non-controlled Pearson's correlation values are reported within brackets.

\begin{tabular}{|c|c|c|c|}
\hline PANAS & CD & PO & SMA \\
\hline Determined & $-0.17^{* * *}\left(0.16^{* * *}\right)$ & $-0.03^{\text {n.s. }}\left(-0.01^{\text {n.s. }}\right)$ & $-0.02^{\text {n.s. }}\left(0.02^{\text {n.s. }}\right)$ \\
\hline Attentive & $-0.11 *(-0.10 *)$ & $-0.06^{\text {n.s. }}\left(-0.04^{\text {n.s. }}\right)$ & $-0.02^{\text {n.s. }}\left(-0.04^{\text {n.s. }}\right)$ \\
\hline Concentrating & $-0.15^{* *}\left(-0.14^{* *}\right)$ & $-0.13^{*}\left(-0.11^{*}\right)$ & $-0.06^{\text {n.s. }}\left(-0.04^{\text {n.s. }}\right)$ \\
\hline Afraid & $0.11^{* *}\left(0.14^{* *}\right)$ & $0.16^{* *}\left(0.19^{* * *}\right)$ & $0.11^{*}\left(0.19^{* * *}\right)$ \\
\hline Upset & $0.13^{* *}\left(0.16^{* * *}\right)$ & $0.15^{* *}\left(0.18^{* * *}\right)$ & $0.12 *\left(0.20^{* * *}\right)$ \\
\hline Nervous & $0.13^{* *}\left(0.15^{* * *}\right)$ & $0.19^{* * *}\left(0.19^{* * *}\right)$ & $0.15^{* *}\left(0.21^{* * *}\right)$ \\
\hline Jittery & $0.21^{* * *}\left(0.23^{* * *}\right)$ & $0.20^{* * *}\left(0.24^{* * *}\right)$ & $0.13^{* *}\left(0.21^{* * *}\right)$ \\
\hline Scared & $0.15^{* *}\left(0.17^{* * *}\right)$ & $0.12 *\left(0.16^{* * *}\right)$ & $0.11^{*}\left(0.18^{* * *}\right)$ \\
\hline Distressed & $0.11^{*}\left(0.13^{* *}\right)$ & $0.11^{*}\left(0.16^{* * *}\right)$ & $0.11^{*}\left(0.19^{* * *}\right)$ \\
\hline Guilty & $0.14^{* *}\left(0.14^{* * *}\right)$ & $0.12 * *\left(0.12^{* *}\right)$ & $0.14^{* *}\left(0.14^{* *}\right)$ \\
\hline Ashamed & $0.18^{* * *}\left(0.20^{* * *}\right)$ & $0.17^{* * *}\left(0.17^{* * *}\right)$ & $0.14^{* *}\left(0.16^{* * *}\right)$ \\
\hline Irritable & $0.09^{\text {n.s. }}\left(0.11^{*}\right)$ & $0.13^{* *}\left(0.15^{* *}\right)$ & $0.09^{\text {n.s. }}\left(0.14^{* *}\right)$ \\
\hline Hostile & $0.13^{* *}\left(0.14^{* *}\right)$ & $0.12 *\left(0.14^{* *}\right)$ & $0.12 *\left(0.15^{* *}\right)$ \\
\hline PANAS_PA & $-0.07^{\text {n.s. }}\left(-0.05^{\text {n.s. }}\right)$ & $0.06^{\text {n.s. }}\left(-0.03^{\text {n.s. }}\right)$ & $0.02^{\text {n.s. }}\left(-0.06^{\text {n.s. }}\right)$ \\
\hline PANAS_NA & $0.19^{* * *}\left(0.22^{* * *}\right)$ & $0.21^{* * *}\left(0.24^{* * *}\right)$ & $0.16^{* * *}\left(0.24^{* * *}\right)$ \\
\hline
\end{tabular}

$\mathrm{PO}=$ phone obsession; $\mathrm{PA}=$ positive affect; $\mathrm{NA}=$ negative affect.

Negative affects appeared instead to be more steadily related with both phubbing and SMA, with almost identical effect sizes. In general, as the phubbing and SMA level increases, so does the negative affect. To better emphasize the relationship that phubbing and social media addiction entertained with negative affect, we discretized phubbing and social media addiction scores according to the respective mean value, as they are normally distributed, and compared these two groups (i.e., above and below $\mathrm{CD}$, PO, and SMA mean values) in terms of negative affect through Welch's $t$-test. Individuals with $\mathrm{CD}\left(\mathrm{t}_{(338)}=-2.89\right.$; $p=0.004 ;$ Cohen's $\mathrm{d}=-0.29), \mathrm{PO}\left(\mathrm{t}_{(408)}=-3.87 ; p<0.001\right.$; Cohen's $\left.\mathrm{d}=-0.38\right)$ and SMA $\left(\mathrm{t}_{(411)}=-5.00 ; p<0.001 ;\right.$ Cohen's $\left.\mathrm{d}=-0.49\right)$ scores above the mean value had on average higher levels of negative affect (Figure 1). 


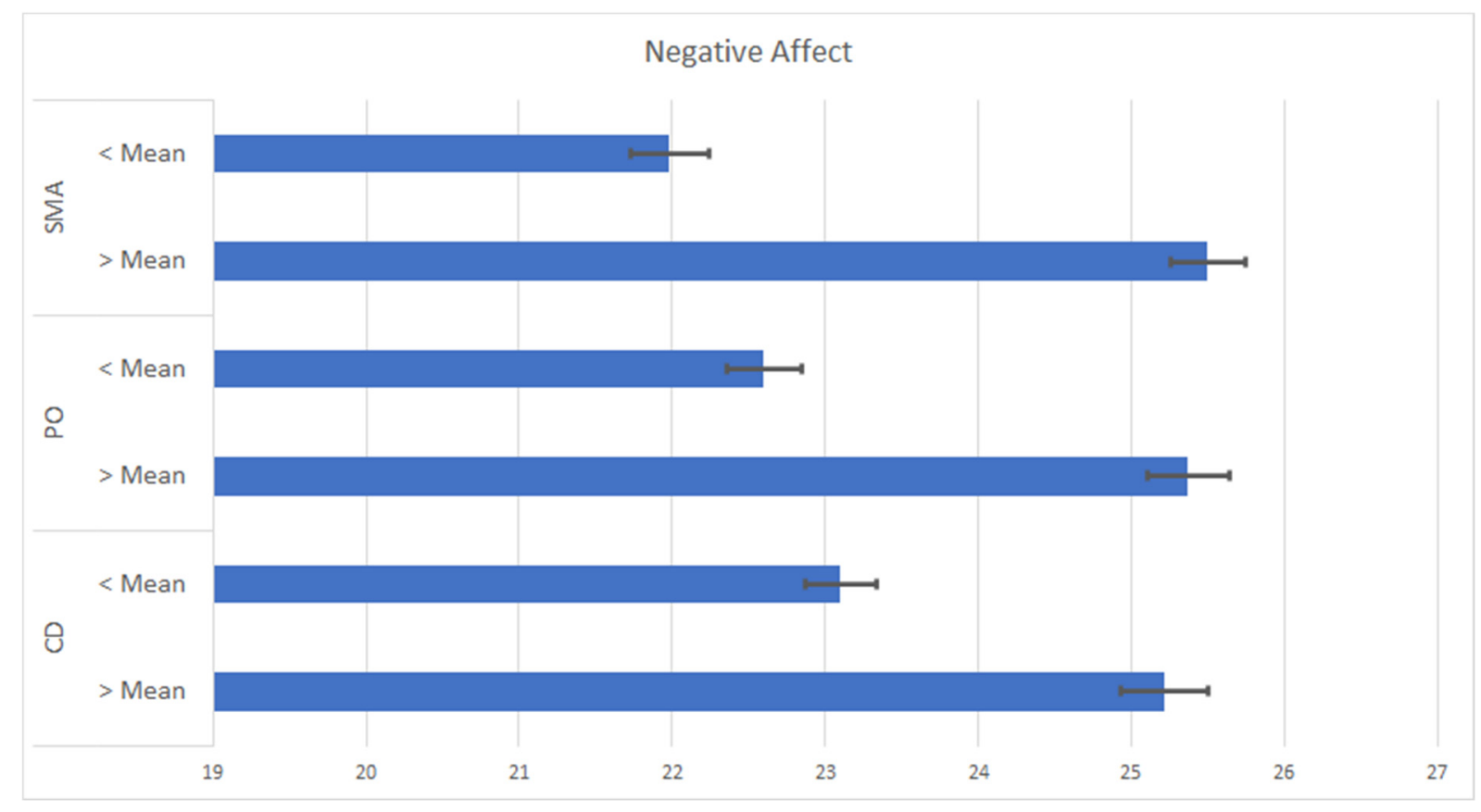

Figure 1. PANAS_NA (negative affect) means comparison between individuals with CD, PO, and SMA scores above or below the observed mean.

\section{Discussion}

In our society, the hyper connection and increased prevalence of ubiquitous technologies have changed our lives and the way we relate to each other. Social media represents nowadays the virtual space where people can interact with others, thus maintaining and increasing social connections and belongingness. This important change in our relationality involved not only young people $[63,64]$, as online communications appear as pervasive within many social environments: from work to family. Although new technologies may facilitate information retrieval and communication between people, they can pose a threat to the quality of our relationships $[35,36,65]$. A paradigmatic example of such a "double-edged sword" is represented by phubbing; from one side, a hurting behavior for the phubbees during a social interaction $[1,50,66]$, but at the same time, an adaptive mechanism for the maintenance of one's identity and the expansion of one's social network [67].

Our study contributed to filling the current literature gap regarding phubber emotional activation, accounting for sex and age effects, considering it as a possible evolutionarily stable coping strategy for self-related motifs (e.g., anxiety reduction, feeling of control), as well as for socially related motifs (i.e., social capital and relationship maintenance) $[35,40]$.

The first hypothesis (i.e., females will have higher scores on the phubbing scale) was partially confirmed. Although females tended to have higher scores than males in phone obsession, no difference between sexes was captured for the communication disturbance dimension. Although females and males showed the same levels of phubbing from a behavioral point of view, our work highlighted how females may experience a higher need for their mobile phone to be at reach $[1,12,27,45]$. A sex difference in social media addiction scores was also observed. In line with the literature $[26,28,30,46]$ and second hypothesis (H2) predictions, females reported higher social media addiction levels. By combining the results coming from $\mathrm{H} 1$ and $\mathrm{H} 2$, females appeared in general to be more vulnerable to developing a dysfunctional use of ICT $[1,12,26,27,30,46]$. This dysfunctional use of information and communication technologies, whether intended as phubbing or social media addiction, seems to be closely linked to participants' age $[13,25,28,30,50,51]$. Both H3 (i.e., phubbing is negatively correlated with age) and H4 (i.e., social media addiction is negatively correlated with age) appeared to be confirmed. Nonetheless, our analyses showed that phubbing, and specifically communication disturbance, entertained 
a smaller relationship with age than social media addiction. In line with the previous literature [13,26,52], we found a statistically significant relationship between social media addiction and phubbing, after controlling for age and sex (H5). In our study, the magnitude of the relationship appeared comparable to those obtained in other works where neither sex nor age were accounted for as confounding variables $[13,26]$.

We did not find differences between males and females regarding emotional activations, in continuity with what was observed in the U.S. normative sample [47]. Differently, emotional activations correlated with social media addiction [30-33], but only with negative ones, thus confirming H6a (i.e., social media addiction positively correlates with NA after controlling for age and sex), but not H6b (i.e., social media addiction negatively correlates with PA after controlling for age and sex). The same type of relationship was detected for both of the phubbing dimensions. Communication disturbance and phone obsession seemed to be positively correlated with negative activations, but not with positive ones. Consequently, only H7a was supported by our results.

Overall, our work provided preliminary evidence concerning phubbers' emotional activation, which was completely absent in the literature up to now. Indeed, a few studies already assessed the emotional repercussions of being phubbed $[35,40,41]$, but no work prior to ours addressed the emotional activation of the individual that engages in phubbing. According to the theory of attachment $[68,69]$, emotions serve as adaptive mechanisms for human survival and sociality. Positive affects bring people closer, while negative affects impair relationships [70]. We already knew from the literature that the phubbee usually experiences negative emotions during phubbing [35], but we now know that even the phubber has a negative activation.

Clearly, our results are correlational and no causation can be inferred. Therefore, we do not know if the phubbers have a negative emotional activation because they do phubbing or, on the contrary, if they do phubbing because they experience those emotions, or if both possibilities are simultaneously true. Moreover, our exploratory results are based on a biased sample owing to a non-random sampling technique and self-selection bias. Another limitation associated with our study is that the closeness of phubbers and people being phubbed was not controlled for, which it should be in future works. Finally, our measure of emotional activations relied on trait rather than state emotional reactivity and self-reported answers that could be prone to overestimation or underestimation of people's moods.

Despite these limitations, the need to reduce phubbing occurrence seems evident, for example, through technological solutions capable of making it less frequent (e.g., batching smartphone notifications) [71,72] and interventions aimed at raising awareness about what happens at a relational level during phubbing $[36,39,73]$.

\section{Conclusions}

Our work presented the emotional activation experienced by the phubber. The display of a stable negative affective activation (i.e., low levels of affective hedonic well-being) was negatively associated with both dimensions of phubbing (i.e., communication disturbance and phone obsession) and social media addiction. Phubbing was also positively and relatively largely correlated with social media addiction. Concerning age and gender, younger people and females appeared to be more prone to engaging in phubbing.

Author Contributions: Conceptualization, A.G., T.R., F.B. and M.D.; methodology, A.G. and M.D.; formal analysis, A.G. and M.D.; investigation, T.R. and B.B.; data curation, A.G., F.B. and M.D.; writing-original draft preparation, A.G., T.R., B.B. and M.D.; writing-review and editing, T.R. and M.D. All authors have read and agreed to the published version of the manuscript.

Funding: This research received no external funding.

Institutional Review Board Statement: The study was conducted according to the guidelines of the Declaration of Helsinki.

Informed Consent Statement: Informed consent was obtained from all subjects involved in the study. 
Data Availability Statement: The data presented in this study are available on request from the corresponding author.

Conflicts of Interest: The authors declare no conflict of interest.

\section{Appendix A}

Table A1. Sociodemographic characteristics of the sample.

\begin{tabular}{cc}
\hline Variable & $\%$ \\
\hline Relationship status & \\
Single & $37.7 \%$ \\
In a relatshionship (without cohabiting) & $37.5 \%$ \\
Married or cohabiting & $22.7 \%$ \\
Divorced or separated & $1.7 \%$ \\
Widower & $0.5 \%$ \\
Yearly income & \\
EUR <10 k€ & $53.0 \%$ \\
EUR 10 k-40 k€ & $36.8 \%$ \\
EUR 40 k-70 k $€$ & $6.7 \%$ \\
EUR 70 k-120 k $€$ & $3.1 \%$ \\
EUR >120 k€ & $0.5 \%$ \\
Education level & \\
Elementary school diploma & $0.2 \%$ \\
Lower secondary school diploma & $3.6 \%$ \\
High school diploma & $39.1 \%$ \\
Bachelor's degree & $25.5 \%$ \\
Master's degree & $27.2 \%$ \\
University Master & $2.6 \%$ \\
Ph.D. & $1.7 \%$ \\
\hline
\end{tabular}

\section{References}

1. Chotpitayasunondh, V.; Douglas, K. How "phubbing" becomes the norm: The antecedents and consequences of snubbing via smartphone. Comput. Hum. Behav. 2016, 63, 9-18. [CrossRef]

2. IJsselsteijn, W.A.; van Baren, J.; van Lanen, F. Staying in Touch: Social Presence and Connectedness through Synchronous and Asynchonous Communication Media. Hum.-Comput. Interact. Theory Pract. 2003, 2, e928.

3. Toch, E.; Levi, I. What Can "people-Nearby" Applications Teach Us about Meeting New People? In Proceedings of the 2012 ACM Conference on Ubiquitous Computing, New York, NY, USA, 5 September 2012; pp. 802-803.

4. Sutko, D.M.; Silva, A.D.S.E. Location-aware mobile media and urban sociability. New Media Soc. 2011, 13, 807-823. [CrossRef]

5. Kemp, S. Digital 2020: July Global Statshot. Available online: https://datareportal.com/reports/digital-2020-july-global-statshot (accessed on 3 November 2021).

6. Gilliland, N. What Will Shape Social Media Marketing in the Second Half of 2020? Econsultancy 2020. Available online: https:// econsultancy.com/what-will-shape-social-media-marketing-trends-in-the-second-half-of-2020/ (accessed on 15 November 2021).

7. Anderson, M.; Jiang, J. Teens, Social Media \& Technology 2018; Pew Research Center: Washington, DC, USA, 2018.

8. Marotta, L.; Pesce, A.; Guazzini, A. Before and after the Quarantine: An Approximate Study on the Psychological Impact of COVID-19 on the Italian Population during the Lockdown Period. Futur. Internet 2020, 12, 229. [CrossRef]

9. Fernández, C.; Vicente, M.A.; Carrillo, I.; Guilabert, M.; Mira, J.J. Factors Influencing the Smartphone Usage Behavior of Pedestrians: Observational Study on "Spanish Smombies". J. Med. Internet Res. 2020, 22, e19350. [CrossRef] [PubMed]

10. Newsham, G.; Drouin, M.; McDaniel, B.T. Problematic phone use, depression, and technology interference among mothers. Psychol. Popul. Media Cult. 2020, 9, 117-124. [CrossRef]

11. Punyanunt-Carter, N.M.; Wrench, J.S. The Impact of Social Media in Modern Romantic Relationships. Rowman and Littlefield Publishing Group: Minneapolis, MN, USA, 2017; ISBN 978-1-4985-4449-8.

12. Karadă̆, E.; Tosuntas, S.B.; Erzen, E.; Duru, P.; Bostan, N.; Şahïn, B.M.; Culha, I.; Babadă̆, B. Determinants of phubbing, which is the sum of many virtual addictions: A structural equation model. J. Behav. Addict. 2015, 4, 60-74. [CrossRef] [PubMed]

13. Guazzini, A.; Duradoni, M.; Capelli, A.; Meringolo, P. An Explorative Model to Assess Individuals' Phubbing Risk. Futur. Internet 2019, 11, 21. [CrossRef]

14. Erzen, E.; Odaci, H.; Yeniçeri, I. Phubbing: Which Personality Traits Are Prone to Phubbing? Soc. Sci. Comput. Rev. 2021, 39, 56-69. [CrossRef] 
15. Pancani, L.; Gerosa, T.; Gui, M.; Riva, P. “Mom, dad, look at me”: The development of the Parental Phubbing Scale. J. Soc. Pers. Relationships 2020, 0265407520964866. [CrossRef]

16. Procentese, F.; Gatti, F.; Di Napoli, I. Families and Social Media Use: The Role of Parents' Perceptions about Social Media Impact on Family Systems in the Relationship between Family Collective Efficacy and Open Communication. Int. J. Environ. Res. Public Health 2019, 16, 5006. [CrossRef] [PubMed]

17. Davey, S.; Davey, A.; Raghav, S.K.; Singh, J.V.; Singh, N.; Blachnio, A.; Przepiórkaa, A. Predictors and consequences of "Phubbing" among adolescents and youth in India: An impact evaluation study. J. Fam. Community Med. 2018, 25, 35-42. [CrossRef]

18. Rainie, L.; Zickuhr, K. Americans' Views on Mobile Etiquette. Pew Res. Cent. Internet Sci. Tech. 2015. Available online: https:/ / www.pewresearch.org/internet/2015/08/26/americans-views-on-mobile-etiquette/ (accessed on 15 November 2021).

19. Afdal, A.; Alizamar, A.; Ifdil, I.; Zadrian, A.; Sukmawati, I.; Zikra, Z.; Ilyas, A.; Fikri, M.; Syahputra, Y. An Analysis of Phubbing Behaviour: Preliminary Research from Counseling Perspective. 2018; pp. 270-273. Available online: http:/ / repository.unp.ac.id/ 23796/ (accessed on 15 November 2021).

20. Frost, R.L.; Rickwood, D.J. A systematic review of the mental health outcomes associated with Facebook use. Comput. Hum. Behav. 2017, 76, 576-600. [CrossRef]

21. T’Ng, S.T.; Ho, K.H.; Low, S.K. Are you "phubbing" me? The Determinants of Phubbing Behavior and Assessment of Measurement Invariance across Sex Differences. Int. Multidiscip. J. Soc. Sci. 2018, 7, 159-190. [CrossRef]

22. Weinstein, A.M. Computer and Video Game Addiction-A Comparison between Game Users and Non-Game Users. Am. J. Drug Alcohol Abus. 2010, 36, 268-276. [CrossRef]

23. Thomée, S.; Härenstam, A.; Hagberg, M. Mobile phone use and stress, sleep disturbances, and symptoms of depression among young adults-a prospective cohort study. BMC Public Health 2011, 11, 66. [CrossRef]

24. Rahman, A.; Duradoni, M.; Guazzini, A. Identification and prediction of phubbing behavior: A data-driven approach. Neural Comput. Appl. 2021, 1-10. [CrossRef]

25. Al-Saggaf, Y.; MacCulloch, R.; Wiener, K. Trait Boredom Is a Predictor of Phubbing Frequency. J. Technol. Behav. Sci. 2018, 4, 245-252. [CrossRef]

26. Balta, S.; Emirtekin, E.; Kircaburun, K.; Griffiths, M.D. Neuroticism, Trait Fear of Missing Out, and Phubbing: The Mediating Role of State Fear of Missing Out and Problematic Instagram Use. Int. J. Ment. Health Addict. 2018, 18, 628-639. [CrossRef]

27. Błachnio, A.; Przepiorka, A. Be Aware! If You Start Using Facebook Problematically You Will Feel Lonely: Phubbing, Loneliness, Self-esteem, and Facebook Intrusion. A Cross-Sectional Study. Soc. Sci. Comput. Rev. 2019, 37, 270-278. [CrossRef]

28. Andreassen, C.S.; Pallesen, S.; Griffiths, M. The relationship between addictive use of social media, narcissism, and self-esteem: Findings from a large national survey. Addict. Behav. 2017, 64, 287-293. [CrossRef] [PubMed]

29. Duradoni, M.; Innocenti, F.; Guazzini, A. Well-Being and Social Media: A Systematic Review of Bergen Addiction Scales. Futur. Internet 2020, 12, 24. [CrossRef]

30. Horwood, S.; Anglim, J. Problematic smartphone usage and subjective and psychological well-being. Comput. Hum. Behav. 2019, 97, 44-50. [CrossRef]

31. Satici, S.A. Facebook Addiction and Subjective Well-Being: A Study of the Mediating Role of Shyness and Loneliness. Int. J. Ment. Health Addict. 2019, 17, 41-55. [CrossRef]

32. Schivinski, B.; Brzozowska-Woś, M.; Stansbury, E.; Satel, J.; Montag, C.; Pontes, H.M. Exploring the Role of Social Media Use Motives, Psychological Well-Being, Self-Esteem, and Affect in Problematic Social Media Use. Front. Psychol. 2020, 11, 617140. [CrossRef] [PubMed]

33. Wolniewicz, C.A.; Tiamiyu, M.F.; Weeks, J.W.; Elhai, J.D. Problematic smartphone use and relations with negative affect, fear of missing out, and fear of negative and positive evaluation. Psychiatry Res. 2018, 262, 618-623. [CrossRef]

34. Gross, E.F.; Juvonen, J.; Gable, S.L. Internet Use and Well-Being in Adolescence. J. Soc. Issues 2002, 58, 75-90. [CrossRef]

35. Chotpitayasunondh, V.; Douglas, K. The effects of "phubbing" on social interaction. J. Appl. Soc. Psychol. 2018, 48, 304-316. [CrossRef]

36. Roberts, J.A.; David, M.E. My life has become a major distraction from my cell phone: Partner phubbing and relationship satisfaction among romantic partners. Comput. Hum. Behav. 2016, 54, 134-141. [CrossRef]

37. Atroszko, P.A.; Balcerowska, J.M.; Bereznowski, P.; Biernatowska, A.; Pallesen, S.; Schou Andreassen, C. Facebook addiction among Polish undergraduate students: Validity of measurement and relationship with personality and well-being. Comput. Hum. Behav. 2018, 85, 329-338. [CrossRef]

38. Du, J.; van Koningsbruggen, G.; Kerkhof, P. A brief measure of social media self-control failure. Comput. Hum. Behav. 2018, 84, 68-75. [CrossRef]

39. Wang, J.-L.; Gaskin, J.; Wang, H.-Z.; Liu, D. Life satisfaction moderates the associations between motives and excessive social networking site usage. Addict. Res. Theory 2016, 24, 450-457. [CrossRef]

40. Teixeira, I.D.N.; Freire, S.E.D.A. Partner Phubbing, Satisfação e Bem-Estar Subjetivo: O Impacto da Tecnologia Digital nos Relacionamentos. Psicogente 2020, 23, 1-15. [CrossRef]

41. Fellesson, M.; Salomonson, N. It takes two to interact-Service orientation, negative emotions and customer phubbing in retail service work. J. Retail. Consum. Serv. 2020, 54, 102050. [CrossRef]

42. Keltner, D.; Haidt, J. Social Functions of Emotions at Four Levels of Analysis. Cogn. Emot. 1999, 13, 505-521. [CrossRef] 
43. Nuñez, T.R.; Radtke, T.; Eimler, S.C. A third-person perspective on phubbing: Observing smartphone-induced social exclusion generates negative affect, stress, and derogatory attitudes. Cyberpsychology J. Psychosoc. Res. Cyberspace 2020, 14. [CrossRef]

44. Bitar, Z.; Hallit, S.; Khansa, W.; Obeid, S. Phubbing and temperaments among young Lebanese adults: The mediating effect of self-esteem and emotional intelligence. BMC Psychol. 2021, 9, 1-9. [CrossRef]

45. Ivanova, A.; Gorbaniuk, O.; Błachnio, A.; Przepiórka, A.; Mraka, N.; Polishchuk, V.; Gorbaniuk, J. Mobile Phone Addiction, Phubbing, and Depression Among Men and Women: A Moderated Mediation Analysis. Psychiatr. Q. 2020, 91, 655-668. [CrossRef]

46. Simsek, A.; Elciyar, K.; Kizilhan, T. A Comparative Study on Social Media Addiction of High School and University Students. Contemp. Educ. Technol. 2019, 10, 106-119. [CrossRef]

47. Watson, D.; Clark, L.A.; Tellegen, A. Development and validation of brief measures of positive and negative affect: The PANAS scales. J. Pers. Soc. Psychol. 1988, 54, 1063-1070. [CrossRef] [PubMed]

48. Crawford, J.R.; Henry, J.D. The Positive and Negative Affect Schedule (PANAS): Construct validity, measurement properties and normative data in a large non-clinical sample. Br. J. Clin. Psychol. 2004, 43, 245-265. [CrossRef] [PubMed]

49. Langvik, E.; Hjemdal, O.; Nordahl, H.M. Personality traits, gender differences and symptoms of anhedonia: What does the Hospital Anxiety and Depression Scale (HADS) measure in nonclinical settings? Scand. J. Psychol. 2016, 57, 144-151. [CrossRef]

50. Al-Saggaf, Y.; MacCulloch, R. Phubbing and Social Relationships: Results from an Australian Sample. J. Relatsh. Res. 2019, 10. [CrossRef]

51. Blackwell, D.; Leaman, C.; Tramposch, R.; Osborne, C.; Liss, M. Extraversion, neuroticism, attachment style and fear of missing out as predictors of social media use and addiction. Pers. Individ. Differ. 2017, 116, 69-72. [CrossRef]

52. Argan, M.; Köse, H.; Özgen, C.; Yalınkaya, B. Do Sports, Take Photo and Share: Phubbing, Social Media Addiction and Narcisism of Body Builders. Eur. J. Phys. Educ. Sport Sci. 2019. [CrossRef]

53. Terraciano, A.; McCrae, R.R.; Costa, P.T., Jr. Factorial and Construct Validity of the Italian Positive and Negative Affect Schedule (PANAS). Eur. J. Psychol. Assess. 2003, 19, 131-141. [CrossRef] [PubMed]

54. Faul, F.; Erdfelder, E.; Lang, A.-G.; Buchner, A. G*Power 3: A flexible statistical power analysis program for the social, behavioral, and biomedical sciences. Behav. Res. Methods 2007, 39, 175-191. [CrossRef]

55. Faul, F.; Erdfelder, E.; Buchner, A.; Lang, A.-G. Statistical power analyses using G*Power 3.1: Tests for correlation and regression analyses. Behav. Res. Methods 2009, 41, 1149-1160. [CrossRef]

56. Kretzschmar, A.; Gignac, G.E. At what sample size do latent variable correlations stabilize? J. Res. Pers. 2019, 80, 17-22. [CrossRef]

57. Forster, J.J. Sample Surveys: Nonprobability Sampling. In International Encyclopedia of the Social E Behavioral Sciences; Smelser, N.J., Baltes, P.B., Eds.; Pergamon: Oxford, UK, 2001; pp. 13467-13470. ISBN 978-0-08-043076-8.

58. Tehseen, S.; Ramayah, T.; Sajilan, S. Testing and Controlling for Common Method Variance: A Review of Available Methods. J. Manag. Sci. 2017, 4, 142-168. [CrossRef]

59. Delacre, M.; Lakens, D.D.; Leys, C. Why Psychologists Should by Default Use Welch's t-test Instead of Student's t-test. Int. Rev. Soc. Psychol. 2017, 30, 92. [CrossRef]

60. Cohen, J. Statistical Power Analysis for the Behavioral Sciences; Routledge: London, UK, 2013; ISBN 978-0-203-77158-7.

61. Thompson, B. Effect sizes, confidence intervals, and confidence intervals for effect sizes. Psychol. Sch. 2007, 44, 423-432. [CrossRef]

62. Gignac, G.; Szodorai, E.T. Effect size guidelines for individual differences researchers. Pers. Individ. Differ. 2016, 102, 74-78. [CrossRef]

63. Villanti, A.C.; Johnson, A.L.; Ilakkuvan, V.; A Jacobs, M.; Graham, A.L.; Rath, J.M. Social Media Use and Access to Digital Technology in US Young Adults in 2016. J. Med. Internet Res. 2017, 19, e196. [CrossRef] [PubMed]

64. Escobar-Viera, C.G.; Shensa, A.; Bowman, N.D.; Sidani, J.E.; Knight, J.; James, A.E.; Primack, B.A. Passive and Active Social Media Use and Depressive Symptoms Among United States Adults. Cyberpsychology Behav. Soc. Netw. 2018, 21, 437-443. [CrossRef]

65. Lapierre, M.A.; Lewis, M.N. Should it stay or should it go now? Smartphones and relational health. Psychol. Popul. Media Cult. 2018, 7, 384-398. [CrossRef]

66. Kadylak, T.; Makki, T.W.; Francis, J.; Cotten, S.R.; Rikard, R.V.; Sah, Y.J. Disrupted copresence: Older adults' views on mobile phone use during face-to-face interactions. Mob. Media Commun. 2018, 6, 331-349. [CrossRef]

67. Chayko, M. Portable Communities: The Social Dynamics of Online and Mobile Connectedness; SUNY Press: New York, NY, USA, 2008; ISBN 978-0-7914-7599-7.

68. Bowlby, J. Attachment and loss: Retrospect and prospect. Am. J. Orthopsychiatry 1982, 52, 664-678. [CrossRef]

69. Bowlby, J. Developmental psychiatry comes of age. Am. J. Psychiatry 1988, 145, 1-10. [CrossRef] [PubMed]

70. Levenson, R.W.; Gottman, J.M. Marital interaction: Physiological linkage and affective exchange. J. Pers. Soc. Psychol. 1983, 45, 587-597. [CrossRef]

71. Fitz, N.; Kushlev, K.; Jagannathan, R.; Lewis, T.; Paliwal, D.; Ariely, D. Batching smartphone notifications can improve well-being. Comput. Hum. Behav. 2019, 101, 84-94. [CrossRef]

72. Park, S.Y.; Baek, Y.M. Two faces of social comparison on Facebook: The interplay between social comparison orientation, emotions, and psychological well-being. Comput. Hum. Behav. 2018, 79, 83-93. [CrossRef]

73. Wang, X.; Xie, X.; Wang, Y.; Wang, P.; Lei, L. Partner phubbing and depression among married Chinese adults: The roles of relationship satisfaction and relationship length. Pers. Individ. Differ. 2017, 110, 12-17. [CrossRef] 